\title{
The Potential Effects of Aliskiren on Atrial Remodeling Induced by Chronic Intermittent Hypoxia in Rats
}

This article was published in the following Dove Press journal: Drug Design, Development and Therapy

\author{
Shuai Miao* \\ Yu Yang* \\ Ruiling Li \\ Li Yin \\ Kai Zhang \\ Lijun Cheng \\ Xiaona Xu \\ Weiding Wang (D) \\ Zhiqiang Zhao \\ Guangping Li
}

Tianjin Key Laboratory of lonic-Molecular Function of Cardiovascular Disease, Department of Cardiology, Tianjin Institute of Cardiology, Second Hospital of Tianjin Medical University, Tianjin 3002 II, People's Republic of China

*These authors contributed equally to this work

\begin{abstract}
Purpose: Atrial remodeling takes part in the pathogenesis of atrial fibrillation (AF). Aliskiren, as a direct renin inhibitor, has been shown to exert protective effects against arrhythmia. The aim of this study was to investigate the potential role of aliskiren in atrial remodeling in a chronic intermittent hypoxia (CIH) rat model.
\end{abstract}

Methods: A total of 45 Sprague-Dawley rats were randomly assigned into three groups ( $\mathrm{n}=15$ per group): control group; $\mathrm{CIH}$ group; and $\mathrm{CIH}$ with aliskiren (CIH-A) group. $\mathrm{CIH}$ and $\mathrm{CIH}-\mathrm{A}$ rats were subjected to $\mathrm{CIH}$ for $6 \mathrm{~h}$ per day for 4 weeks. Atrial fibrosis was evaluated using Masson's trichrome staining. Electrophysiological tests were conducted in the isolated perfused hearts to assess the atrial effective refractory period and inducibility of AF. Atrial ionic remodeling was measured using the whole-cell patch-clamp technique, and Western blotting and real-time quantitative polymerase chain reactionwere performed to evaluate changes in ion channels.

Results: CIH induced obvious collagen deposition, and the abnormal fibrosis was significantly attenuated by aliskiren. The inducibility of AF was increased significantly in the $\mathrm{CIH}$ group compared with the control and CIH-A groups ( $23 \pm 24.5 \%$ vs $2.0 \pm 4.2 \%$ vs $5.0 \pm 7.0 \%$, respectively; $P<0.05)$. Compared with the control group, the densites of the calcium current $\left(I_{\mathrm{CaL}}\right)$ and sodium current $\left(I_{\mathrm{Na}}\right)$ were reduced significantly in the $\mathrm{CIH}$ group $\left(I_{\mathrm{CaL}}:-3.16\right.$ $\pm 0.61 \mathrm{pA} / \mathrm{pF}$ vs $-7.13 \pm 1.98 \mathrm{pA} / \mathrm{pF} ; I_{\mathrm{Na}}:-50.97 \pm 8.71 \mathrm{pA} / \mathrm{pF}$ vs $-132.58 \pm 25.34 \mathrm{pA} / \mathrm{pF}$, respectively; all $P<0.05)$. Following intervention with aliskiren, the reductions in $I_{\mathrm{CaL}}$ and $I_{\mathrm{Na}}$ were significantly improved, and the ionic modeling changes assessed at the mRNA and protein levels were also significantly improved.

Conclusion: $\mathrm{CIH}$ could alter atrial modeling and subsequently promote the occurrence and development of AF, which could be attenuated by treatment with aliskiren.

Keywords: atrial fibrillation, aliskiren, chronic intermittent hypoxia, atrial remodeling

\section{Introduction}

In clinical practice, atrial fibrillation (AF), which is a frequently encountered tachyarrhythmia, often leads to the development of cardiovascular or cerebrovascular diseases. ${ }^{1}$ Thus far, the mechanisms of AF have not been fully understood. A few studies have suggested that autonomic imbalance is closely associated with $\mathrm{AF}$, and the autonomic nervous system could be regulated by the renin-angiotensin-aldosterone system (RAAS). ${ }^{2,3}$ Atrial ionic and structural remodeling is the substrate and mechanism for the process of AF. ${ }^{4}$ Therefore, suppression of atrial remodeling may be a novel treatment for AF.
Correspondence: Zhiqiang Zhao; Guangping

Tianjin Key Laboratory of lonic-Molecular Function of Cardiovascular Disease, Department of Cardiology, Tianjin Institute of Cardiology, Second Hospital of Tianjin Medical University, Tianjin 3002I I, People's

Republic of China

$\mathrm{Tel}+86-22-88328368$

Fax +86-22-2826II 58

Email tic_ticardiol@I26.com;

zzqzzqzhiqiang@163.com 
It has been suggested that chronic intermittent hypoxia (CIH) could induce atrial remodeling and increase $\mathrm{AF}$ inducibility. ${ }^{5}$ The negative effects of $\mathrm{CIH}$ include autonomic imbalance, swings in blood pressure, and changes in stress factors, which all contribute to AF. ${ }^{6,7}$ The model of $\mathrm{AF}$ induced by $\mathrm{CIH}$ in rats is close to the pathogenesis of $\mathrm{AF}^{8,9}$ so the model has been widely applied.

In addition, numerous studies have focused on the association between the RAAS and AF. ${ }^{10}$ Inhibiting RAAS may have a preventive effect on AF. Aliskiren is an orally active, direct renin inhibitor with sufficient bioavailability, ${ }^{11}$ which can bind to renin and prevent angiotensinogen converting to angiotensin-I (Ang-I). Altarejo Marin et al ${ }^{12}$ suggested that aliskiren contributed toward protection from fibrosis by interfering with fibrogenic cytokines and oxidative stress. Our previous experiments indicated that aliskiren could attenuate atrial electrical remodeling in a canine model of rapid atrial pacing. ${ }^{13}$ Therefore, we designed this study to determine whether aliskiren could prevent atrial remodeling in $\mathrm{CIH}$ rats.

\section{Materials and Methods}

\section{Experimental Protocol}

Our study followed the ARRIVE guidelines and was approved by the Experimental Animal Administration Committee of Tianjin Medical University and Tianjin Municipal Commission for Experimental Animal Control.

A total of 45 Sprague-Dawley male rats (age: 8 weeks; weight: $200-250 \mathrm{~g}$ ) were randomly assigned into three groups ( $\mathrm{n}=15$ per group): control group; $\mathrm{CIH}$ group; and $\mathrm{CIH}$ with aliskiren treatment (CIH-A) group. Rats subjected to $\mathrm{CIH}$ were placed in a chamber with a controlled oxygen concentration between $8 \%$ and $21 \%$. When the oxygen concentration increased to $21 \%$, the system could automatically release nitrogen to reduce the concentration to $8 \%$ and maintain this condition for 50 s. Subsequently, oxygen would be released into the chamber to increase the concentration to $21 \%$ and the cycles were initiated. Rats were subjected to $\mathrm{CIH}$ for $6 \mathrm{~h}$ per day for 4 weeks. Rats in the CIH-A group were infused with aliskiren intragastrically via gavage $(20 \mathrm{mg} / \mathrm{kg}$ /day) for 4 weeks. After $\mathrm{CIH}$, five random rats from each group were used for whole-cell patch clamp, five animals were selected for global electrophysiological and histological analyses, and the remaining rats were used for Western blotting and polymerase chain reaction (PCR).

\section{Hemodynamic Measurements}

Rats were anesthetized with $3 \%$ phenobarbitone $(3 \mathrm{~mL} / \mathrm{kg}$ ) through intraperitoneal injection. After anesthesia, we cut off the skin along the centerline of the neck and then the carotid artery was separated carefully. The distal end of the carotid artery was ligatured and a minor break was made at the proximal part of the carotid artery. We inserted a Millar pressure cannula into the carotid artery, and heart rate (HR), systolic blood pressure (SBP), diastolic blood pressure (DBP), and mean blood pressure (MBP) were recorded through a biological function detection system.

\section{Solutions}

Tyrode's solution ( $\mathrm{pH} 7.4$, adjusted with sodium hydroxide) was composed of: sodium chloride $(136 \mathrm{mmol} / \mathrm{L})$, magnesium dichloride $(0.8 \mathrm{mmol} / \mathrm{L})$, potassium chloride $(5.4 \mathrm{mmol} / \mathrm{L})$, calcium chloride $(1.80 \mathrm{mmol} / \mathrm{L}), \mathrm{NaH}_{2} \mathrm{PO}_{4}$ $(0.33 \mathrm{mmol} / \mathrm{L}), \mathrm{N}-2$-hydroxyethylpiperazine-N'-2-ethane sulfonic acid (HEPES) $(10 \mathrm{mmol} / \mathrm{L})$, and glucose $(10$ $\mathrm{mmol} / \mathrm{L}$ ). Kraft-Bruhe (KB) solution ( $\mathrm{pH} 7.4$, adjusted with potassium hydroxide) contained potassium chloride $(20 \mathrm{mmol} / \mathrm{L})$, glucose $(10 \mathrm{mmol} / \mathrm{L})$, monopotassium phosphate $(10 \mathrm{mmol} / \mathrm{L}), \mathrm{L}$-glutamic acid $(70 \mathrm{mmol} / \mathrm{L})$, ethylene glycol tetraacetic acid $(10 \mathrm{mmol} / \mathrm{L})$, taurine $(10$ $\mathrm{mmol} / \mathrm{L}$ ), and $0.5 \%$ bovine serum albumin. Enzyme solution was obtained using $100 \mathrm{U} / \mathrm{mL}$ collagenase-II and $0.5 \%$ bovine serum albumin dissolved in calcium-free Tyrode's solution. The pipette solution ( $\mathrm{pH} 7.25)$ was composed of cesium chloride $(20 \mathrm{mmol} / \mathrm{L})$, magnesium dichloride $(1 \mathrm{mmol} / \mathrm{L})$, potassium aspartate $(80 \mathrm{mmol} / \mathrm{L})$, ethylene glycol tetraacetic acid $(10 \mathrm{mmol} / \mathrm{L})$, N-2-hydroxyethylpiperazine-N'-2-ethane sulfonic acid $(10 \mathrm{mmol} / \mathrm{L})$, guanosine-5'-triphosphate $(0.1 \mathrm{mmol} / \mathrm{L})$, tetraethylammonium chloride $(20 \mathrm{mmol} / \mathrm{L})$, adenosine triphosphate-magnesium $(5 \mathrm{mmol} / \mathrm{L})$, and phosphocreatine disodium ( $5 \mathrm{mmol} / \mathrm{L}$ ). Tyrode's solution was also used as the extracellular solution to record the calcium current $\left(I_{\mathrm{CaL}}\right)$ and sodium current $\left(I_{\mathrm{Na}}\right)$.

\section{Isolation of Atrial Cells}

We performed a sternotomy and isolated the hearts according to the method described in previous studies. ${ }^{14,15}$ The hearts were rapidly cut out and placed in Tyrode's solution at $4{ }^{\circ} \mathrm{C}$ to extrude any residual blood. Subsequently, we cannulated the aorta and linked it to the Langendorff perfusion system full of Tyrode's solution which was dissolved with oxygen. We maintained the perfusion pressure 
at $100 \mathrm{cmH}_{2} \mathrm{O}$ and the perfusion rate was 1 drop per second. Following cardiac arrest, the hearts were perfused with a solution containing collagenase-II for $40 \mathrm{~min}$. Softened atrial tissue was cut into $10 \mathrm{~mL} \mathrm{~KB}$ solution, washed and gently blown for $2 \mathrm{~min}$; next, the fragment was filtered from the solution. After dilution with an additional $10 \mathrm{~mL}$ of $\mathrm{KB}$ solution, the mixture was centrifuged. After discarding the supernatant, the atrial cells were immersed in $80 \mathrm{~mL}$ of $\mathrm{KB}$ solution. Subsequently, the isolated cells were maintained at indoor temperature for $1 \mathrm{~h}$

\section{Data Acquisition}

Part of the solution including the atrial cells was transferred into a $2 \mathrm{~mL}$ box fixed on the platform and an inverted microscope (Olympus Corp., Tokyo, Japan) was used to observe the atrial myocytes. Atrial cells were deposited in the box for 10 min and gently perfused with Tyrode's solution. The bacilliform cells with distinct stripes were selected.

Atrial cell ionic currents were recorded using an amplifier (Axon 200B; Axon, USA). Glass microelectrodes, with an outer diameter of $1.5 \mathrm{~mm}$ and inner diameter of $1.1 \mathrm{~mm}$, were produced by a pipette puller (ModelP97; Sutter, USA). Microelectrodes which had a tip resistance of 2-5 $\Omega$ were used.

\section{Protocol of Atrial Effective Refractory Period (AERP) Measurement and AF Induction}

The isolation of hearts from rats was performed using the method mentioned at Isolation of atrial cells section. Tyrode's solution used for in vitro electrophysiology was buffered by $\mathrm{NaHCO}_{3}$, not HEPES. We used Tyrode's solution to perfuse the hearts, maintained at $80-95 \mathrm{mmHg}$, through the ascending aorta. The solution was maintained at $37^{\circ} \mathrm{C}$ and dissolved with $95 \%$ oxygen and $5 \%$ carbon dioxide. Three electrodes were punctured into the heart, one each into the left and right atria and the right ventricle. Electrophysiological measurement and recording were executed using software (Electrophysiological Recording System; Hong Tong Company, Shanghai, China). When measuring the AERP, the interval of stimulation (S1S2), starting at basic cycle lengths of $100 \mathrm{~ms}$, was shortened by $2 \mathrm{~ms}$ per step. The AERP was identified as the longest interval that could not capture the atria. Subsequently, the induction of $\mathrm{AF}$ was detected by a 3-s burst pacing with a cycle length of $50 \mathrm{~ms}$. The process was executed 10 times in each animal, and the AF inducibility was calculated as the ratio of the number of times of induced $\mathrm{AF} / 10$. AF was identified as a rapid and irregular heart rhythm on a computer electrocardiogram which persisted for $>1 \mathrm{~s}$.

\section{Histological Studies}

Following global electrophysiology, the atria were cut, dehydrated, and embedded in paraffin. Atrial fibrosis was visualized by Masson's trichrome staining: normal tissue appeared red, while fibers were blue. The extent of the fibrotic tissue was evaluated by the collagen fraction, which was calculated as the blue area//red area + blue area). We applied Image-Pro Plus 6.0 software to analyze the images.

\section{Protein Extraction and Western Blotting}

We used radioimmunoprecipitation assay lysate (RIPA, KeyGen Biotech, Nanjing, China) and phenylmethylsulfonyl fluoride (PMSF, protease inhibitor; KeyGen Biotech, Nanjing, China) to extract total protein from the atrial tissue. The lysates were centrifuged at $12,000 \mathrm{rpm}$ for 20 min and the liquid supernatant was gathered. Then, 10 $\mu \mathrm{g}$ protein was added into each gap equally and run on a $6 \%$ sodium dodecyl sulfate-polyacrylamide gel electrophoresis (SDS-PAGE) gel. Proteins with different molecular weights were separated by electrophoresis and transferred onto polyvinylidene fluoride (PVDF) membranes. The membranes were sealed with 5\% skim milk for $1 \mathrm{~h}$ at room temperature and subsequently put into primary antibodies overnight at $4^{\circ} \mathrm{C}$ for incubation. The primary antibodies were: $\beta$-actin (1:4000; Proteintech, USA), Cav1.2 (1:1000; Affinity, USA), and Nav1.5 $\alpha$ (1:1000; Cell Signaling Technology, USA). The membrane was then washed three times with TBST and incubated with the secondary antibody for $1 \mathrm{~h}$ at room temperature. The membrane was washed three more times with TBST and then visualized with Rhea ECL. Image Lab software was applied to evaluate the band intensity.

\section{Real-Time Quantitative PCR}

Total RNA was extracted using the trizol reagent, isopropanol, and chloroform. RNA samples were quantified using fluorescence spectrophotometry and considered to be pure when the optical density 260:280 was $>1.8$. Subsequently, we obtained cDNA through reverse transcription using a reverse transcription kit (TIANGEN Biotech, Beijing, China) and real-time quantitative PCR 
was performed on a 7500 Real-Time PCR System with SYBR green fluorescent dyes (TIANGEN Biotech). All reactions were performed at least twice, with at least three replicates for each sample. Cycle threshold $(\mathrm{Ct})$ data were collected, and the $2^{-\Delta \Delta \mathrm{Ct}}$ method was used to compare the mRNA levels. GAPDH was used as the internal control. The primers used were 5'-GGCCACAGACATTGTTT CTGAGT-3' and 5'-TTGGAACCTCCAGGAGAAATGT AC-3' (calcium voltage-gated channel subunit alpha1C [CACNA1C], 288 bp) and 5'-AGTGCCAGCCTCGT CTCATA-3' and 5'-ACCAGCTTCCCATTCTCAGC-3' (GAPDH, 261 bp).

\section{Statistical Analysis}

SPSS version 18.0 software was utilized to analyze the data, and all quantitative data are presented as the mean \pm standard deviation. The one-way ANOVA test was applied for comparisons among the three groups. The LSD $t$-test was used to make comparisons between two groups. A two-tailed $P$-value $<0.05$ denoted a statistically significant difference.

\section{Results}

\section{Hemodynamic Parameters}

The findings of the hemodynamic parameter analysis are presented in Table 1. No significant differences in heart rate were observed between the three groups $(P>0.05)$. The results showed that the SBP, DBP, and MBP were significantly lower in the CIH-A group than in the $\mathrm{CIH}$ group $(113.84 \pm 33.03 \mathrm{mmHg}$ vs $151.42 \pm 23.39 \mathrm{mmHg}, 81.05$ $\pm 21.51 \mathrm{mmHg}$ vs $105.17 \pm 15.57 \mathrm{mmHg}$, and $91.97 \pm 24.98$ mmHg vs $120.59 \pm 13.67 \mathrm{mmHg}$, respectively; all $P<0.01$ ).

\section{Pathology}

Typical pathological sections in three groups are illustrated in Figure 1. Atrial tissue of rats from the control group

Table I Hemodynamic Parameters in the Three Groups $(n=15$ in Each Group)

\begin{tabular}{|l|l|l|l|l|}
\hline & Control & CIH & CIH-A & P value \\
\hline HR (bPm) & $321.78 \pm 97.47$ & $332.76 \pm 93.48$ & $286.14 \pm 110.04$ & 0.648 \\
SBP (mmHg) & $128.63 \pm 19.67$ & $151.42 \pm 23.39^{*}$ & $113.84 \pm 33.03^{* \Delta}$ & 0.011 \\
DBP (mmHg) & $90.78 \pm 18.67$ & $105.17 \pm 15.57^{*}$ & $81.05 \pm 21.51^{*}$ & 0.026 \\
MBP (mmHg) & $103.40 \pm 16.14$ & $120.59 \pm 13.67^{*}$ & $91.97 \pm 24.98^{* \Delta}$ & 0.008 \\
\hline
\end{tabular}

Notes: Values are given as mean $\pm S D$. $* P<0.01$ vs corresponding value in control group; ${ }^{\Delta} P<0.01$ vs corresponding value in $\mathrm{ClH}$ group.

Abbreviations: HR, heart rate; SBP, systolic blood pressure; DBP, diastolic blood pressure; MBP, mean blood pressure. appeared normal (Figure 1A). CIH induced obvious atrial interstitial collagen deposition throughout the tissue (Figure 1B). Moreover, the abnormal fibrosis was significantly attenuated by aliskiren treatment (Figure 1C). The percentage of the atrial collagen fraction for the quantitative evaluation of atrial fibrosis is shown in Figure 1D. The atrial collagen fraction in the CIH group was significantly higher than that recorded in the control group (7.72 $\pm 1.89 \%$ vs $0.69 \pm 0.23 \%$, respectively; $P<0.01$ ). This percentage was significantly decreased in the CIH-A group versus the $\mathrm{CIH}$ group $(3.58 \pm 0.71 \%$ vs $7.72 \pm 1.89 \%$, respectively; $P<0.01)$.

\section{$I_{\mathrm{CaL}}$ and $I_{\mathrm{Na}}$ Current Density}

Following rupture of the cell membrane, we waited for 3 min to minimize the accumulative effect on $I_{C}$ aL rundown. The results regarding $I_{\mathrm{CaL}}$ current densities are shown in Figure $2 \mathrm{~A}$. We initially clamped at $-40 \mathrm{mV}$ with $200-\mathrm{ms}$ pulse duration, followed by a depolarization pulse ranging from -50 to $+60 \mathrm{mV}$ to generate typical $I_{\mathrm{CaL}}$. We found that the density of $I_{\mathrm{CaL}}$ was significantly decreased in the $\mathrm{CIH}$ group. The average maximum peak $I_{\mathrm{CaL}}$ density in the $\mathrm{CIH}$ group was significantly lower than in the control group $(-3.16 \pm 0.61 \mathrm{pA} / \mathrm{pF}$ vs $-7.13 \pm 1.98 \mathrm{pA} / \mathrm{pF}$, respectively; $\mathrm{n}=10$ cells each; $P<0.05)$. In the $\mathrm{CIH}-\mathrm{A}$ group, the average maximum peak $I_{\mathrm{CaL}}$ density was significantly increased to $-4.98 \pm 1.27 \mathrm{pA} / \mathrm{pF}$ ( $\mathrm{n}=10$ cells) compared with that calculated for the $\mathrm{CIH}$ group $(P<0.05)$.

The overall results for the $I_{\mathrm{Na}}$ current densities are illustrated in Figure 2B. The methods in measuring $\mathrm{I}_{\mathrm{CaL}}$ were applied prior to membrane rupture to avoid contaminating effects. Typical $I_{\mathrm{Na}}$ was drawn by a depolarizing pulse ranging from $-100 \mathrm{mV}$ to $+40 \mathrm{mV}$ after clamping at $-90 \mathrm{mV}$ with $200-\mathrm{ms}$ pulse duration. The $I_{\mathrm{Na}}$ density was significantly decreased in the CIH group $(-50.97 \pm 8.71 \mathrm{pA} /$ $\mathrm{pF} ; \mathrm{n}=8$ cells $)$ versus the control group $(-132.58 \pm 25.34 \mathrm{pA} /$ $\mathrm{pF} ; \mathrm{n}=8$ cells; $P<0.05)$. The downtrend was significantly improved following intervention with aliskiren, and the average maximum peak $I_{\mathrm{Na}}$ density in the CIH-A group was $-93.50 \pm 27.94 \mathrm{pA} / \mathrm{pF}$ ( $\mathrm{n}=8$ cells; $P<0.05$ ).

\section{Electrophysiological Studies}

In the electrophysiological studies, no significant difference was observed between the left and right AERPs among the three groups (Table 2). After burst pacing, the representative episodes of different groups are illustrated in Figure 3A (control group), Figure 3B (CIH group) and Figure $3 \mathrm{C}$ (CIH-A group). As shown in Figure 3D, the rate 


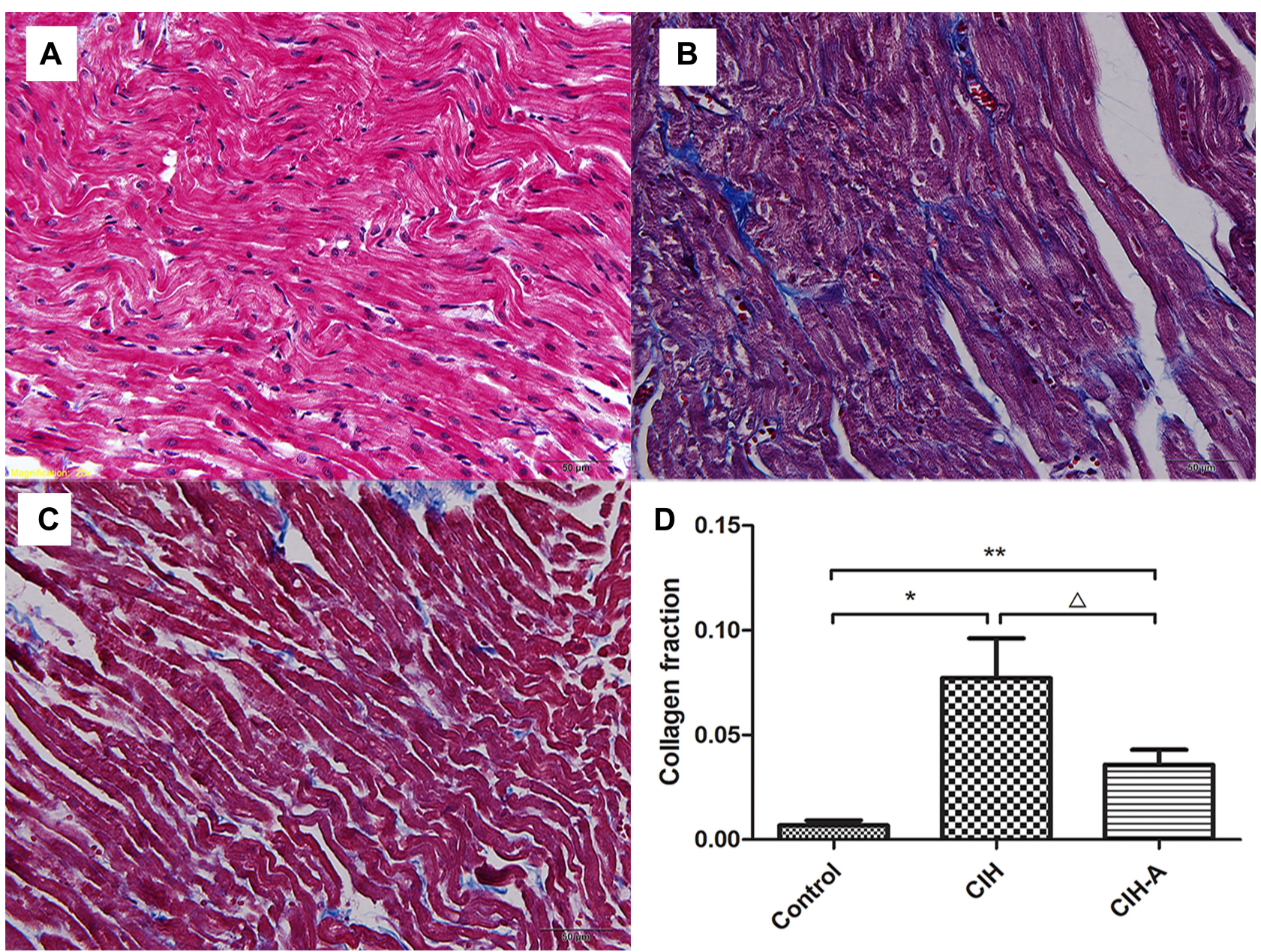

Figure I Representative photomicrographs of Masson-stained atrial sections from rats in the control (A), $\mathrm{ClH}(\mathbf{B})$, and $\mathrm{ClH}-\mathrm{A}(\mathbf{C})$ groups $(\mathrm{n}=5)$. (D) Atrial collagen fraction in the three groups. ${ }^{*}<0.01$ between control group and $\mathrm{ClH}$ group. ${ }^{*} * \mathrm{P}<0.01$ between control group and $\mathrm{ClH}-\mathrm{A}$ group. ${ }^{\Delta} \mathrm{P}<0.0 \mathrm{I}$ between $\mathrm{ClH}$ group and $\mathrm{ClH}-\mathrm{A}$ group.

of $\mathrm{AF}$ inducibility was increased in the $\mathrm{CIH}$ group (23 $\pm 24.5 \% ; \mathrm{n}=5)$ versus the control group $(2.0 \pm 4.2 \% ; \mathrm{n}=5$; $P<0.01)$. This increase in AF inducibility was significantly attenuated following treatment with aliskiren $(5.0 \pm 7.0 \%$; $\mathrm{n}=5 ; P<0.01)$.

\section{Expression of CACNAIC and SCN5A}

The mRNA expression levels of CACNA1C and SCN5A are shown in Figure 4. In Figure 4A, CACNA1C was reduced in the $\mathrm{CIH}$ group versus the control group. This downregulation was significantly attenuated by aliskiren treatment. Similarly, the mRNA levels of SCN5A were significantly suppressed by $\mathrm{CIH}$ and were improved after intervention with aliskiren (Figure 4B).

\section{Changes in Levels of Cavl.2 and Navl.5 $\alpha$} Subsequent Western blotting experiments confirmed the above results for the expression of Nav1.5 $\alpha$ and Cav1.2
(Figure 5). In Figure 5A, CIH significantly downregulated the expression of Cav1.2 compared to the control rats $(P<0.05)$. Conversely, the protein expression of Cav1.2 was markedly increased in the CIH-A rats compared to the $\mathrm{CIH}$ rats $(P<0.05)$. No statistically significant difference was found in the expression of Cav1.2 between the control and CIH-A groups $(P>0.05)$. In Figure 5B, the expression of Nav1.5 $\alpha$ was significantly decreased in the $\mathrm{CIH}$ group $(P<0.05)$. Administration of aliskiren reversed the reduction in the protein levels of Nav1.5 $\alpha$; however, no significant difference was observed compared to the $\mathrm{CIH}$ group $(P>0.05)$.

\section{Discussion}

$\mathrm{AF}$ is a widespread cardiovascular disease and its incidence rate gradually rises with the aging of populations. ${ }^{16}$ Atrial remodeling may be one mechanism involved in the occurrence of AF. ${ }^{17,18}$ Unfortunately, the pathophysiology of this complex heart rhythm disorder remains poorly 
A

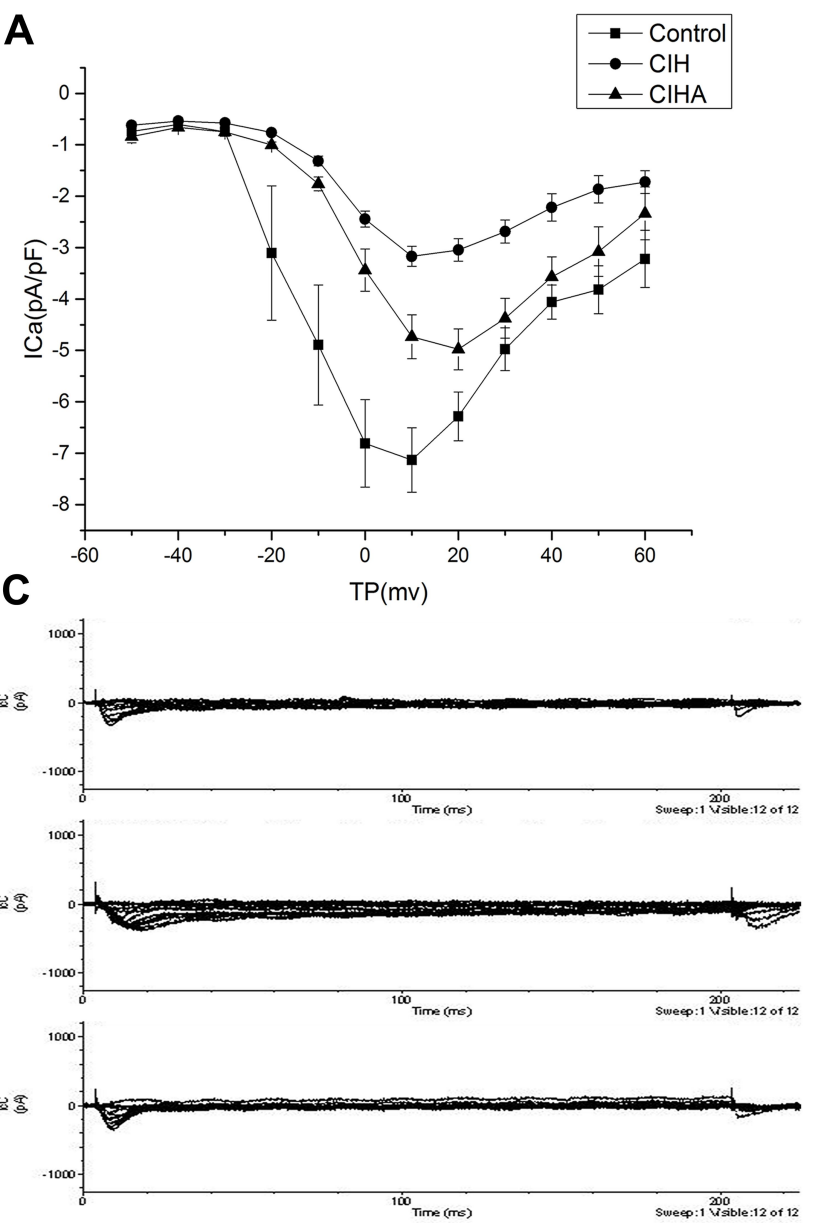

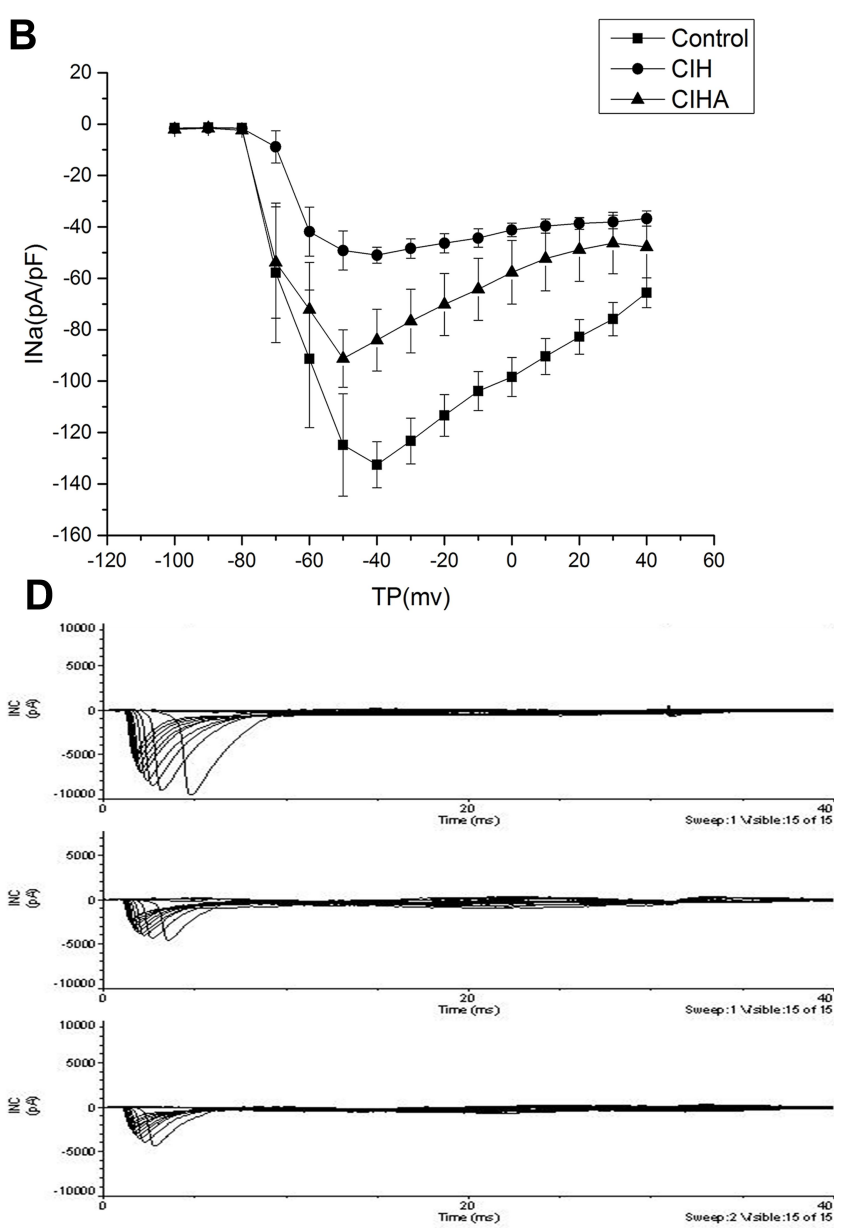

Figure $2 I-V$ curves for $I_{\mathrm{CaL}}$ (A) and $I_{\mathrm{Na}}$ (B) current densities in the three groups. (C) recording traces for sodium in the three groups.

Abbreviation: TP, test potential.

understood. $\mathrm{CIH}$ is one of numerous risk factors which could promote the occurrence of AF. Animal experiments showed that $\mathrm{CIH}$ was an important mediator of enhanced atrial vulnerability and susceptibility to $\mathrm{AF} .{ }^{19}$ Goudis and Ketikoglou $^{20}$ described that obstructive sleep apnea was associated with AF, which may implicate the pathophysiological mechanisms of AF. In addition, Zhang et $\mathrm{al}^{21}$ showed that the percentage of the atrial collagen fraction

Table 2 Electrophysiological Parameters in the Three Groups

\begin{tabular}{|l|l|l|l|l|l|}
\hline & BCL & Control & CIH & CIH-A & P value \\
\hline LAERP (ms) & 150 & $35.80 \pm 7.21$ & $32.20 \pm 5.61$ & $30.60 \pm 7.54$ & 0.238 \\
RAERP (ms) & 150 & $35.00 \pm 6.41$ & $33.00 \pm 3.91$ & $31.20 \pm 7.06$ & 0.374 \\
AF inducibility & 50 & $2.0 \% \pm 4.2 \%$ & $23 \% \pm 24.5 \% *$ & $5.0 \% \pm 7.0 \% * \Delta$ & 0.008 \\
\hline
\end{tabular}

Notes: Values are given as mean $\pm S D$. $* P<0.01$ vs corresponding value in control group; ${ }^{\Delta}<<0.01$ vs corresponding value in $\mathrm{ClH}$ group.

Abbreviations: $B C L$, basic cycle length; RAERP, right atrial effective refractory period; LAERP, left atrial effective refractory period. in the $\mathrm{CIH}$ group was significantly increased compared with the values recorded in the control and intervention groups. Therefor, we created an atrial fibrosis model by $\mathrm{CIH}$ for further experimentation in this study. In our study, we compared the percentage of the atrial collagen fraction among three groups. We obtained obvious atrial fibrosis after $6 \mathrm{~h}$ of $\mathrm{CIH}$ per day for 4 weeks and the abnormal fibrosis was significantly attenuated by aliskiren.

Aliskiren, which is used in antihypertensive therapy, is a direct renin inhibitor, blocking most upstream components of RAAS. ${ }^{22}$ It has been reported that aliskiren can regress left ventricular remodeling as effectively as losartan. ${ }^{23}$ Ye et $\mathrm{al}^{24}$ suggested that aliskiren reduced the expression of angiotensin II type 1 receptor (AT1R) in mice with type 2 diabetes mellitus. In addition, our previous study proposed that aliskiren could improve ionic remodeling in rapid atrial pacing dogs through a decrease in Ang-II. ${ }^{13}$ We also found that aliskiren could inhibit the 


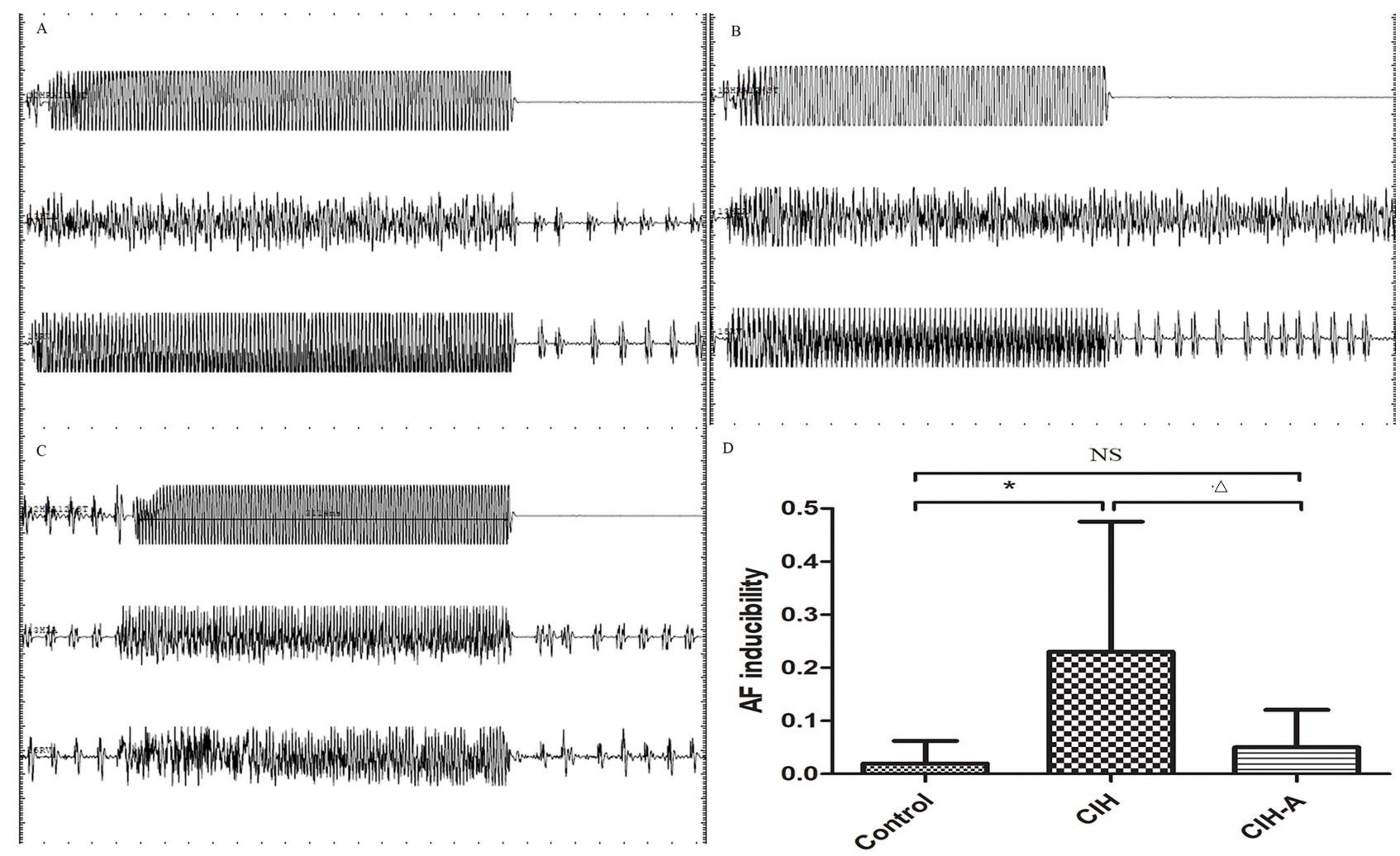

Figure 3 Representative episodes induced by burst pacing in the three groups $(n=5)$. (A) Control group. (B) $\mathrm{ClH}$ group. (C) CIH-A group. (D) AF inducibility in the three groups. ${ }^{*}<0.01$ between control group and $\mathrm{ClH}$ group. ${ }^{{ }^{P}}<<0.0 \mathrm{I}$ between $\mathrm{ClH}$ group and $\mathrm{ClH}-\mathrm{A}$ group. NS, no significance.
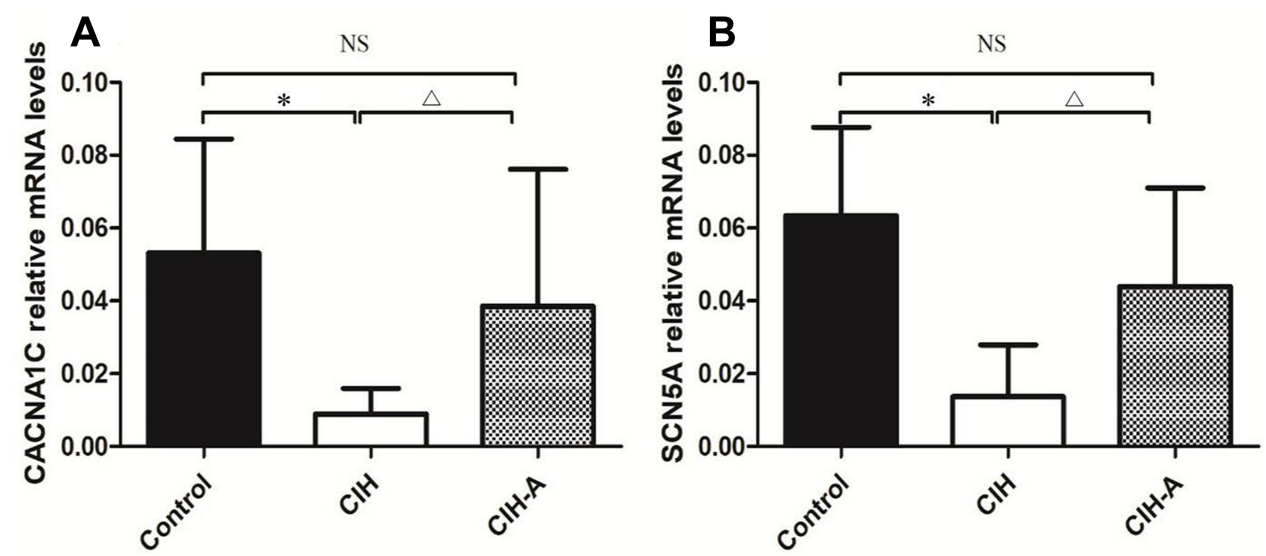

Figure $4 \mathrm{mRNA}$ expression levels of CACNAIC (A) and SCN5A (B) in the three groups $(n=5)$, detected by real-time quantitative polymerase chain reaction. $* P<0.01$ between control group and $\mathrm{ClH}$ group. ${ }^{\Delta} \mathrm{P}<0.0 \mathrm{I}$ between $\mathrm{ClH}$ group and $\mathrm{ClH}$-A group. NS, no significance.

expression of transforming growth factor- $\beta_{1}\left(\mathrm{TGF}-\beta_{1}\right)$, downregulate MEK/ERK 1/2 signal pathways, and reduce the inflammatory reaction of interleukin. ${ }^{25}$ These findings revealed the protective role of aliskiren on atrial remodeling. In the present study, we observed that aliskiren may potentially prevent the occurrence of AF. Firstly, aliskiren could reduce blood pressure, including SBP, DBP, and MBP. Secondly, aliskiren improved the atrial fibrosis induced by CIH. Thirdly, aliskiren attenuated atrial electrical remodeling, which is explained in the next paragraph.

We executed the first study to investigate the efficacy of aliskiren on atrial ionic remodeling in $\mathrm{CIH}$ rats. Atrial electrical remodeling is the result of changes in ion channels, pumps, and exchangers. ${ }^{26}$ We obtained a significant decrease in CACNA1C mRNA expression in $\mathrm{CIH}$ rats, 
A

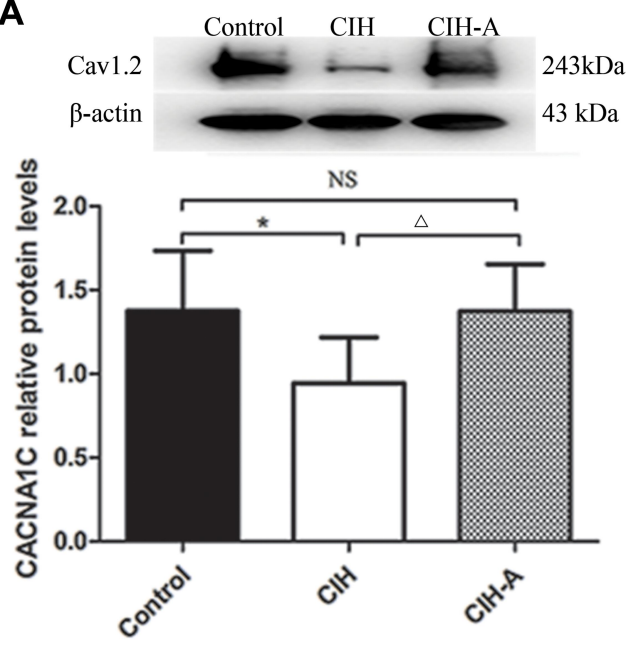

B
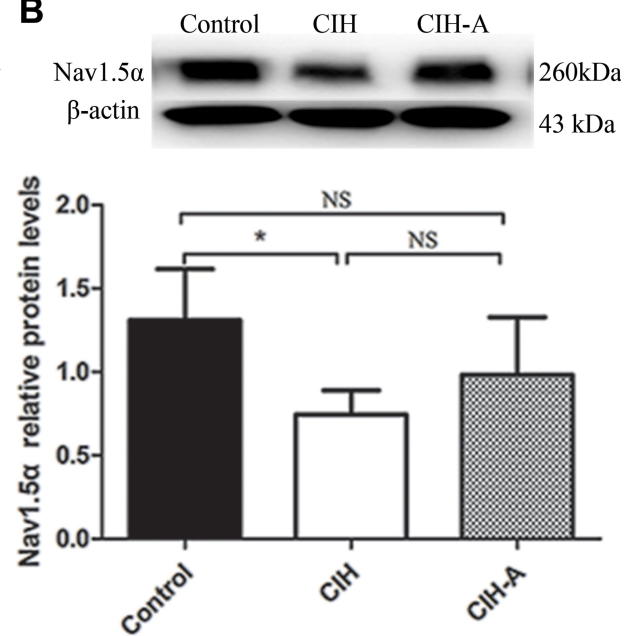

Figure 5 Protein expression of Cavl.2 (A) and $\mathrm{Navl} .5 \alpha(\mathbf{B})$ in the three groups $(\mathrm{n}=5)$, determined by Western blotting. $* P<0.0 \mathrm{I}$ between control group and $\mathrm{ClH}$ group. ${ }^{\Delta} P<0.0$ I between $\mathrm{ClH}$ group and $\mathrm{ClH}-\mathrm{A}$ group. NS, no significance.

which was confirmed at the protein and ion channel levels. Following the development of $\mathrm{AF}$, plenty of $\mathrm{Ca}^{2+}$ ions are released from the sarcoplasmic reticulum $\left(\mathrm{Ca}^{2+}\right.$ overloading $)$ and the capacity of $\mathrm{Ca}^{2+}$ handling becomes abnormal. ${ }^{27}$ Subsequently, the intracellular $\mathrm{Ca}^{2+}$ increases to resist $\mathrm{Ca}^{2+}$ overloading, which results in the activation of the nuclear factor of activated $\mathrm{T}$ cells. The nuclear factor of activated T cells is transferred into the nucleus and further inhibits the encoding of CACNA1C, thereby resulting in the reduction of $I_{\mathrm{CaL}}$, which contributes to the maintenance of $\mathrm{AF}^{28}$

Nav1.5, which is part of a group of ion channels called voltage-gated sodium channels, mainly participates the initial upstroke of the action potential. ${ }^{29}$ The Nav1.5 $\alpha$ subunit is encoded by the SCN5A gene, mutations of which can cause dysfunction of $I_{\mathrm{Na}}$ and then lead to increasing susceptibility to atrial arrhythmias. ${ }^{30,31}$ Ziyadeh-Isleem et $\mathrm{al}^{32}$ reported that SCN5A mutation decreased the peak sodium current and the late sodium current, which can disrupt repolarization and prolong the action potential duration, thereby providing the substrates for the occurrence and persistence of $\mathrm{AF}^{33}$ In addition, Liu et $\mathrm{al}^{34}$ obtained a significant decrease in $I_{\mathrm{Na}}$ in a diabetic rabbit model of AF. As in the previous study, we found that the $I_{\mathrm{Na}}$ current was significantly decreased in $\mathrm{CIH}$ rats, which was confirmed at the protein and mRNA levels in our study. Furthermore, the decrease in $I_{\mathrm{Na}}$ could be reversed after aliskiren intervention.

However, no significant change in AERP was found by in vitro electrophysiology in the present study. Apart from the $\mathrm{Ca}^{2+}$ and $\mathrm{Na}^{+}$currents, AERP was also determined by $\mathrm{K}^{+}$currents. There are plenty of potassium channels predominantly and widely distributed in the atria, such as $\mathrm{K}_{\mathrm{v}} 1.5, \mathrm{~K}_{\mathrm{v}} 4.3$, and $\mathrm{K}_{\mathrm{ir}} 3.4 .{ }^{35}$ It is complicated to detect the association between $\mathrm{K}^{+}$channels and AERP. Taking $\mathrm{K}_{\mathrm{v}} 1.5$ as an example, Ford et $\mathrm{al}^{36}$ reported that blockade of $\mathrm{K}_{\mathrm{v}} 1.5$ channels induced AERP shortening at a low stimulation rate $(1 \mathrm{~Hz})$ but prolongation at higher rates $(4 \mathrm{~Hz}$ and higher). Since we did not record $\mathrm{K}^{+}$currents and the corresponding ionic proteins, it is possible that there was no difference in AERP among the three groups.

\section{Limitations}

Some limitations to this study should be noted. Firstly, the atrium was not divided into the left and right atria. It is unknown that whether the left atrium performs differently from the right atrium in AF. Secondly, we did not evaluate $\mathrm{Ca}^{2+}$-related proteins, including the $\mathrm{Na}^{+} / \mathrm{Ca}^{2+}$ exchanger, ryanodine receptors, and $\mathrm{K}^{+}$-related ionic proteins. This may explain the unchanged AERP noted among the three groups. Thirdly, the quantity of samples used for analysis of each part of the experiment was small, and more samples should be added to confirm the present results in the future. In addition, further studies should investigate the electrophysiology of the heart in vitro, more ion channels and the efficacy of aliskiren in $\mathrm{CIH}$ rats.

\section{Conclusion}

In this study, we observed that the density of $I_{\mathrm{CaL}}$ and $I_{\mathrm{Na}}$ induced downregulation significantly in the $\mathrm{CIH}$ group. This reduction was improved by treatment with aliskiren, as shown by protein and mRNA analyses. We also observed that $\mathrm{CIH}$ induced obvious collagen deposition 
and the abnormal fibrosis was significantly attenuated by aliskiren. Therefore, aliskiren may prevent AF by attenuating atrial remodeling in $\mathrm{CIH}$ rats.

\section{Funding}

This work was supported by the Program of Natural Science Foundation of China (No. 81370300), Key Laboratory Science Foundation of Second Hospital of Tianjin Medical University (Nos 2019ZDSYS07 and 2019ZDSYS05), and Tianjin Natural Science Foundation (No. 17JCQNJC11400).

\section{Disclosure}

The authors declare no conflicts of interest for this work.

\section{References}

1. Schotten U, Verheule S, Kirchhof P, Goette A. Pathophysiological mechanisms of atrial fibrillation: a translational appraisal. Physiol Rev. 2011;91(1):265-325. doi:10.1152/physrev.00031.2009

2. Scridon A, Şerban RC, Chevalier P. Atrial fibrillation: neurogenic or myogenic? Arch Cardiovasc Dis. 2018;111(1):59-69. doi:10.1016/j. acvd.2017.11.001

3. Konno S, Hirooka Y, Kishi T, Sunagawa K. Sympathoinhibitory effects of telmisartan through the reduction of oxidative stress in the rostral ventrolateral medulla of obesity-induced hypertensive rats. J Hypertens. 2012;30 (10):1992-1999. doi:10.1097/HJH.0b013e328357fa98

4. Jalife J, Kaur K. Atrial remodeling, fibrosis, and atrial fibrillation. Trends Cardiovasc Med. 2015;25(6):475-484. doi:10.1016/j.tcm.2014.12.015

5. Latina JM, Estes NAM, Garlitski AC, et al. The relationship between obstructive sleep apnea and atrial fibrillation: a complex interplay. Pulm Med. 2013;2013:1-11. doi:10.1155/2013/621736

6. Geovanini GR, Lorenzi-Filho G. Cardiac rhythm disorders in obstructive sleep apnea. $J$ Thorac Dis. 2018;10(Suppl 34):S4221S4230. doi:10.21037/jtd.2018.12.63

7. Hohl M, Linz B, Bohm M, et al. Sleep apnea and atrial arrhythmogenesis. Curr Cardiol Rev. 2014;10:362-368. doi:10.2174/1573403X1004140707125137

8. Dimitri H, Ng M, Brooks AG, et al. Atrial remodeling in obstructive sleep apnea: implications for atrial fibrillation. Heart Rhythm. 2012;9:321-327. doi:10.1016/j.hrthm.2011.10.017

9. Ma ZW, Zhang K, Wang WD, et al. [Tolvaptan attenuates atrial remodeling in rats undergoing chronic intermittent hypoxia via miRNA-21]. Zhonghua Xin Xue Guan Bing Za Zhi. 2019;47 (8):614-621. Chinese. doi:10.3760/cma.j.issn.0253-3758.2019 08.005

10. Yongjun Q, Huanzhang S, Wenxia Z, Hong T, Xijun X. From changes in local RAAS to structural remodeling of the left atrium: a beautiful cycle in atrial fibrillation. Herz. 2015;40(3):514-520. doi:10.1007/s00059-013-4032-7

11. Pool JL, Schmieder RE, Azizi M, et al. Aliskiren, an orally effective renin inhibitor, provides antihypertensive efficacy alone and in combination with valsartan. Am $J$ Hypertens. 2007;20(1):11-20. doi:10.1016/j.amjhyper.2006.06.003

12. Altarejo Marin T, Machado Bertassoli B, Alves de Siqueira de Carvalho A, Feder D. The use of aliskiren as an antifibrotic drug in experimental models: A systematic review. Drug Dev Res. 2020;81 (1):114-126. doi:10.1002/ddr.21610

13. Zhao Z, Wang X, Li J, et al. Protective effects of aliskiren on atrial ionic remodeling in a canine model of rapid atrial pacing. Cardiovasc Drugs Ther. 2014;28(2):137-143. doi:10.1007/s10557-014-6509-x
14. Yue L, Feng J, Li GR, Nattel S. Transient outward and delayed rectifier currents in canine atrium: properties and role of isolation methods. Am J Physiol. 1996;270(6 Pt 2):H2157-H2168. doi:10.11 52/ajpheart.1996.270.6.H2157

15. Li D, Melnyk P, Feng J, et al. Effects of experimental heart failure on atrial cellular and ionic electrophysiology. Circulation. 2000;101 (22):2631-2638. doi:10.1161/01.CIR.101.22.2631

16. Camm AJ, Kirchhof P, Lip GY, et al. Guidelines for the management of atrial fibrillation: the Task Force for the Management of Atrial Fibrillation of the European Society of Cardiology (ESC). Europace. 2010;12(10):1360-1420.

17. Pellman J, Lyon RC, Sheikh F. Extracellular matrix remodeling in atrial fibrosis: mechanisms and implications in atrial fibrillation. $J \mathrm{Mol}$ Cell Cardiol. 2010;48(3):461-467. doi:10.1016/j.yjmcc.2009.09.001

18. Gumprecht J, Domek M, Lip GYH, Shantsila A. Invited review: hypertension and atrial fibrillation: epidemiology, pathophysiology, and implications for management. J Hum Hypertens. 2019;33 (12):824-836. doi:10.1038/s41371-019-0279-7

19. Zhang K, Zhao L, Ma Z, et al. Doxycycline attenuates atrial remodeling by interfering with microRNA-21 and downstream phosphatase and tensin homolog (PTEN)/Phosphoinositide 3-Kinase (PI3K) signaling pathway. Med Sci Monit. 2018;24:5580-5587. doi:10.12659/MSM.909800

20. Goudis CA, Ketikoglou DG. Obstructive sleep and atrial fibrillation: pathophysiological mechanisms and therapeutic implications. Int J Cardiol. 2017;230:293-300. doi:10.1016/j.ijcard.2016.12.120

21. Zhang K, Ma Z, Wang W, et al. Beneficial effects of tolvaptan on atrial remodeling induced by chronic intermittent hypoxia in rats. Cardiovasc Ther. 2018;36(6):e12466. doi:10.1111/1755-5922.12466

22. Nussberger J, Wuerzner G, Jensen C, Brunner HR. Angiotensin II suppression in humans by the orally active renin inhibitor Aliskiren (SPP100): comparison with enalapril. Hypertension. 2002;39(1):E1E8. doi:10.1161/hy0102.102293

23. Solomon SD, Appelbaum E, Manning WJ, et al. Effect of the direct renin inhibitor aliskiren, the angiotensin receptor blocker losartan, or both on left ventricular mass in patients with hypertension and left ventricular hypertrophy. Circulation. 2009;119(4):530-537. doi:10.1161/CIRCULATIONAHA.108.826214

24. Ye Y, Qian J, Castillo AC, Perez-Polo JR, Birnbaum Y. Aliskiren and valsartan reduce myocardial AT1 receptor expression and limit myocardial infarct size in diabetic mice. Cardiovasc Drugs Ther. 2011;25 (6):505-515. doi:10.1007/s10557-011-6339-Z

25. Zhao Z, Chen Y, Li W, et al. Aliskiren protecting atrial structural remodeling from rapid atrial pacing in a canine model. Naunyn Schmiedebergs Arch Pharmacol. 2016;389(8):863-871. doi:10.1007/s00210-016-1249-Z

26. Nattel S, Harada M. Atrial remodeling and atrial fibrillation: recent advances and translational perspectives. $J$ Am Coll Cardiol. 2014;63 (22):2335-2345. doi:10.1016/j.jacc.2014.02.555

27. Nattel S, Dobrev D. The multidimensional role of calcium in atrial fibrillation pathophysiology: mechanistic insights and therapeutic opportunities. Eur Heart J. 2012;33(15):1870-1877. doi:10.1093/eurheartj/ehs079

28. Qi XY, Yeh YH, Xiao L, et al. Cellular signaling underlying atrial tachycardia remodeling of L-type calcium current. Circ Res. 2008;103(8):845-854. doi:10.1161/CIRCRESAHA.108.175463

29. Escande D, Coulombe A, Faivre JF, Deroubaix E, Coraboeuf E. Two types of transient outward currents in adult human atrial cells. Am J Physiol. 1987;252(1 Pt 2):H142-H148. doi:10.1152/ajpheart.1987.252.1.H142

30. Patino GA, Isom LL. Electrophysiology and beyond: multiple roles of $\mathrm{Na}+$ channel $\beta$ subunits in development and disease. Neurosci Lett. 2010;486(2):53-59. doi:10.1016/j.neulet.2010.06.050

31. Hayashi K, Tada H, Yamagishi M. The genetics of atrial fibrillation. Curr Opin Cardiol. 2017;32(1):10-16. doi:10.1097/HCO.0000000000000356

32. Ziyadeh-Isleem A, Clatot J, Duchatelet S, et al. A truncating SCN5A mutation combined with genetic variability causes sick sinus syndrome and early atrial fibrillation. Heart Rhythm. 2014;11(6):10 15-1023. doi:10.1016/j.hrthm.2014.02.021 
33. Zhang K, Ma Z, Song C, Duan X, Yang Y, Li G. Role of ion channels in chronic intermittent hypoxia-induced atrial remodeling in rats. Life Sci. 2020;254:117797. doi:10.1016/j.1fs.2020.117797

34. Liu C, Liu R, Fu H, et al. Pioglitazone attenuates atrial remodeling and vulnerability to atrial fibrillation in alloxan-induced diabetic rabbits. Cardiovasc Ther. 2017;35(5):e12284. doi:10.1111/1755-59 22.12284
35. Voigt N, Dobrev D. Atrial-Selective Potassium Channel Blockers. Card Electrophysiol Clin. 2016;8(2):411-421. doi:10.1016/j.ccep.2016.02.005

36. Ford J, Milnes J, El Haou S, et al. The positive frequency-dependent electrophysiological effects of the IKur inhibitor XEN-D0103 are desirable for the treatment of atrial fibrillation. Heart Rhythm. 2016;13(2):555-564. doi:10.1016/j.hrthm.2015.10.003

\section{Publish your work in this journal}

Drug Design, Development and Therapy is an international, peerreviewed open-access journal that spans the spectrum of drug design and development through to clinical applications. Clinical outcomes, patient safety, and programs for the development and effective, safe, and sustained use of medicines are a feature of the journal, which has also been accepted for indexing on PubMed Central. The manuscript management system is completely online and includes a very quick and fair peer-review system, which is all easy to use. Visit http://www. dovepress.com/testimonials.php to read real quotes from published authors. 